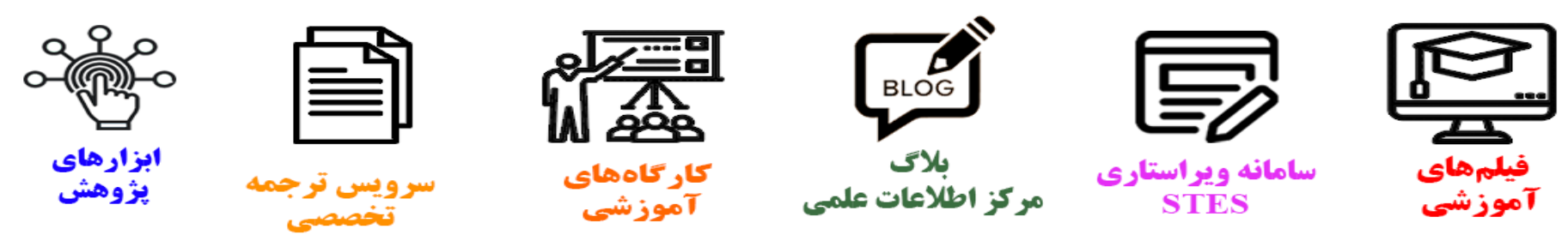

\title{
(c)
}

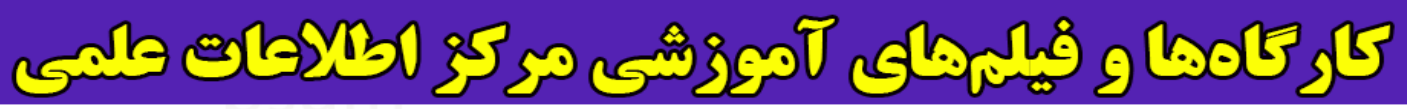
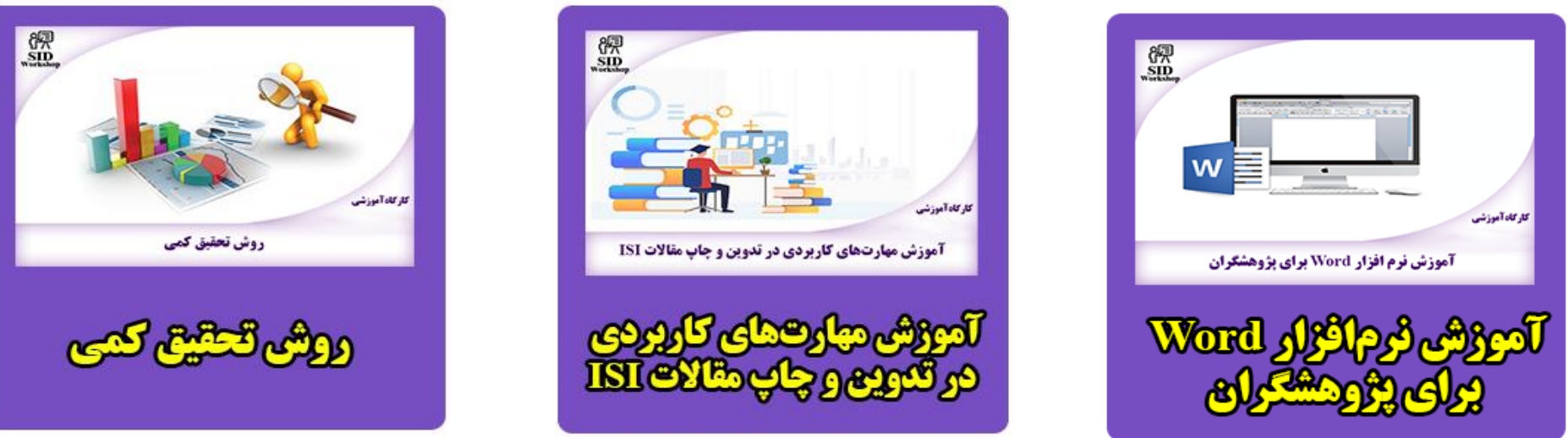


\title{
International Journal of Engineering
}

Journal Homepage: www.ije.ir

\section{Systematic Approach to Design a Finite Time Convergent Differentiator in Second Order Sliding Mode Controller}

\author{
S. M. Rakhtala, A. Ranjbar, R. Ghaderi* \\ Faculty of Electrical and Computer Engineering, Babol University of Technology, Iran
}

\section{PAPER INFO}

\section{Paper history:}

Received 30 November 2012

Received in revised form 23 January 2013

Accepted 18 April 2013

\section{Keywords:}

Finite Time Convergent

Nonlinear Modeling

Twisting Algorithm

Convergent Differentiator

Pressure Regulation

\section{$A B S T R$ A $C$ T}

This paper presents a systematic approach to design a Lyapunov based super twisting differentiator. The differentiator will be shown convergent in a finite time whilst the relevant time is accurately estimated. This differentiator is the main part to establish the sliding surface in higher order sliding mode. The differentiator is used in the prescribed control structure to regulate pressures of hydrogen and oxygen of a nonlinear Polymer Electrolyte Membrane Fuel Cells (PEMFCs) to prolong the stack life. The aim of the control strategy is to minimize and keep the deviation between the pressures of hydrogen and oxygen. The deviation forms a sliding surface, where its appropriate differentiation is required in the control law. It is the reason for reconstructing finite time derivatives in a closed-loop control. Finally, simulation result and a comparative study verify the performance of the proposed differentiator and the control structure to provide convergent estimator in finite time.

doi: 10.5829/idosi.ije.2013.26.11b.11

\begin{tabular}{|c|c|c|c|}
\hline \multicolumn{4}{|c|}{ NOMENCLATURE } \\
\hline $\mathrm{P}_{\mathrm{H}_{2} \text { ref }}$ & Reference partial pressure of hydrogen & $\mathrm{H}_{2} \mathrm{O}_{\mathrm{A} \text { out }}$ & Purged water mass flow rate \\
\hline$P_{\mathrm{O}_{2} \text { ref }}$ & Reference partial pressure of oxygen & $o_{2 \text { in }}$ & Inlet mass flow rate of oxygen into the cathode \\
\hline$P_{H_{2}}$ & Partial pressure of hydrogen & $N_{2 \text { in }}$ & Inlet mass flow rate of nitrogen into the cathode \\
\hline$P_{\mathrm{H}_{2} \mathrm{O}} \mathrm{A}$ & Partial pressure of water in anode side & $O_{2 \text { used }}$ & Reacted mass flow rate of oxygen \\
\hline$P_{O_{2}}$ & Partial pressure of oxygen & $O_{2 o u t}$ & Outlet flow rate of oxygen \\
\hline$P_{N_{2}}$ & Partial pressure of nitrogen & $N_{2 o u t}$ & Outlet flow rate of nitrogen \\
\hline $\mathrm{P}_{2} \mathrm{O}_{\mathrm{C}}$ & Partial pressure of water in cathode side & $\mathrm{H}_{2} \mathrm{O}_{\mathrm{C} \text { produced }}$ & Reacted water mass flow rate \\
\hline $\mathrm{H}_{2}$ in & Inlet mass flow rate of hydrogen & $\mathrm{H}_{2} \mathrm{O}_{\mathrm{C} \text { in }}$ & Water mass flow rate into the cathode \\
\hline$H_{2}$ used & Reacted mass flow rate of hydrogen & $\mathrm{H}_{2} \mathrm{O}_{\mathrm{Cout}}$ & Water mass flow rate out \\
\hline$H_{2}$ out & Outlet flow rate of hydrogen & $\mathrm{H}_{2} \mathrm{O}_{m b r}$ & Water flow rate across membrane \\
\hline $\mathrm{H}_{2} \mathrm{O}_{\mathrm{A}}$ in & Water mass flow rate into the anode & $T$ & Convergence time of any trajectory \\
\hline $\mathrm{H}_{2} \mathrm{O}_{m b r}$ & Water flow rate across membrane & $T_{u f}$ & Uniform convergence time \\
\hline$\delta_{1}$ & Sliding surface & $T_{f . t}$ & Finite time of compact set \\
\hline$\delta_{2}$ & Derivative of sliding surface & $Q$ & Positive definite matrix \\
\hline$u_{\max }$ & Maximum value of control signal & $P$ & Symmetric and positive definite matrix \\
\hline$\alpha_{m}, \alpha_{M}$ & Controller parameter & $\lambda_{\max }\{P\}$ & Maximum Eigen value of $\mathrm{P}$ matrix \\
\hline$\sigma$ & Positive constant for Lyapunov function & $\lambda_{\min }\{P\}$ & Minimum Eigen value of $\mathrm{P}$ matrix \\
\hline
\end{tabular}

${ }^{*}$ Corresponding Author Email: r__ghaderi@sbu.ac.ir. (R. Ghaderi) 


\section{INTRODUCTION}

A fuel cell (FC) is an electrochemical energy resource to convert chemical energy into electrical and thermal energy. There are types of fuel cells which can generate electrical power ranging from $\mathrm{mW}$ to $\mathrm{MW}$ [1]. Efficiency of PEM fuel cells operation is dependent on the control mechanism. This justifies studying new alternatives control specifically of the higher order. Investigating and implementing advanced controllers may significantly improve PEM fuel cells efficiency and lifetime. This needs for a proper PEMFC model in a multi-input multi-output (MIMO) representation. A small signal model was primarily developed by Lu-Ying Chiu in 2004 through linearization about the operating point. Due to wide range and variety of disturbance a linear control is failed to provide a satisfactory performance[2] . Purkrushpan et al. [3-5] derived a PEMFC model to consider flow characteristics, dynamics of the compressor, manifold (anode and cathode), reactant partial pressures and membrane humidity. The linear model of PEMFC is obtained through a Jacobean linearization using a Taylor series expansion at a nominal operating point. In addition to uncertainties in parametric coefficients for each cell on kinetic and electrochemical foundations, the linearization technique also produces another kind of uncertainty. Accordingly, in some control applications e.g. in sensor-less based one, the model may be insufficient. Furthermore, it fails to achieve a satisfactory performance under large disturbances.

W. K. Na and the colleagues in $[6,7]$ presented a nonlinear controller for their nonlinear model.

Simulation studies showed performance of the proposed nonlinear control with respect to that of linear. However, the proposed nonlinear controller could not guarantee the robustness against operational parametric uncertainties.

An $H_{\infty}$ robust control based on feedback linearization technique is suggested to regulate anode and cathode sides pressure[8]. This technique provided better transient responses whilst guaranteeing a stable operation for the system. Recently, Winston GarciaGabin and co-workers in [9] proposed a robust control approach through a sliding mode control to control the oxygen excess ratio. Since this important factor is regulated via compressor input voltage, any fluctuation in the input signal causes an immediate fluctuation on the stoichiometry regime which degrades the overall performance of the stack. Meanwhile, pressure drop at two sides of the membrane should be kept less than a critical value depending on the employed material (usually less than 500 mbar). Therefore, the fluctuation may generate physical damage on the membrane between the anode and the cathode. These constraints motivated researchers to design high order sliding mode instead of normal one i.e. SMC. This includes a robust control of air feed motor-compressor of PEMFC which is addressed in [10-13]. Talj et al. [10, 11] developed a robust controller based on high order sliding mode to regulate the oxygen excess ratio of fuel cell through a turbo compressor. A super twisting algorithm (STA) has been used to stabilize the system against chattering in $[12,13]$.

The super twisting algorithm usage was raised from distinct robust features of the sliding mode techniques. This STA provides a control signal smoother with respect to the standard first-order sliding mode. Laghrouche and Matraji designed (in 2010) and applied (in 2012) a higher order sliding mode robust controller to regulate sides' pressure of Membrane Electrode Assembly (MEA). In this report, derivative terms of the sliding surface is provided by the Levant differentiator. However, there is no estimation of the convergence time of the used differentiator towards the surface given [14, 15].

An aim is to control anode and cathode pressure such that the pressure drop $\Delta P$ of MEA is stabilized. This, subsequently, reduces sudden pressures exerted to MEA and increases the life time. In the present study, a second-order sliding mode controller (SOSMC) with twisting algorithm will be used. However, this HOSM controller needs availability of higher-order derivatives of sliding variable. Lack of instant derivatives of sliding variables $S, \dot{S}, \ldots, S^{(r)}$ is a major problem to implement HOSM controller. Theoretical differentiator is sensitive to the output and the sliding surface noise. An efficient recursive structure differentiator is proposed by Levant $[16,17]$ which is continued to be developed by Usai et al. [18] by presenting a sub-optimal based one.

These differentiators construct derivatives of the sliding variables. Since the estimation will be used in a control topology, the action time of the controller has be known in advance. However, this is a drawback of that differentiator when they offer no estimation of the convergence time.

1. 1. MAIN Contribution In the current research, a step by step algorithm is proposed to design the differentiator. Furthermore, a Lyapunov function is candidate to proof of the convergence as well as making the estimation of the convergence time possible.

The designed differentiator is used within a second order sliding mode controller based on twisting algorithm. The performance of the proposed procedure is verified when it is used to minimize deviations between the hydrogen and oxygen partial pressures in a PEMFC.

Indeed controller needs information about the time derivative of the sliding manifold $S$. Accordingly a second order sliding mode controller in combination with a routine procedure of differentiator as an output- 
feedback controller is designed. This procedure uses a second order sliding mode to estimate successive derivatives of the measured error signal up to $n-1$ order. An overall configuration is as shown in Figure 1. Another novelty is determining the estimation time of derivatives i.e. finite time convergence is guaranteed. This facility allows the designer to sufficiently apply a controller when this time ends. This makes the whole system stabilized in a finite time. Strong Lyapunov functions for super-twisting algorithms have also been presented. In this approach the necessary laws to candidate designing Lyapunov function are presented. The presented Lyapunov function is synthesized for uniform convergence to origin and also estimation of finite time convergence. Finally, the waiting and elapsed time for estimation of derivatives have been determined. Indeed, the proposed technique offers the following benefits:

1. The controller works in a wide range of the operating range of the fuel cell without restriction to a particular linearized operation point.

2. It is found robust against uncertainty and in noisy circumstances with respect to other traditional alternatives.

3. Anode and cathode pressure is controlled using a systematic super twisting differentiator which makes a prior estimation of the convergence time possible.

4. Fast enough with respect to the Levant differentiator and also others works $[14,15]$.

The paper is organized as follows:

Section 2 introduces a model for PEMFC. In Section 3 second order sliding mode controller is described. Furthermore, a higher order sliding mode controller is design in this section. Section 4, presents a step by step differentiator as a systematic approach. Simulation results and comparative study of second order sliding mode control with respect to other controllers of its kind is presented in Section 5. Finally, a conclusion closes the work in Section 6.

\section{NONLINEAR DYNAMIC MODEL OF PEM FUEL CELL}

This study mainly is a nonlinear control of pressure of anode and cathode gases of a specific PEMFC model.

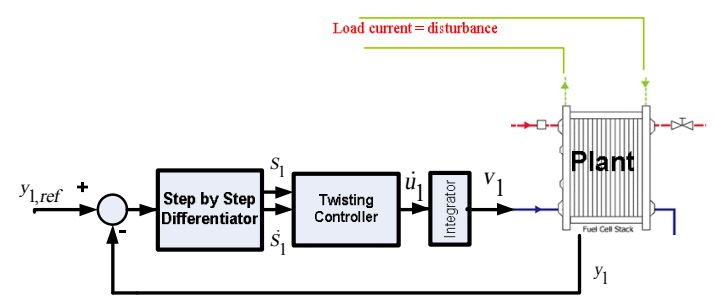

Figure 1. Proposed control structure
Accordingly, a nonlinear state space model of PEM fuel cell is developed. Partial pressure of hydrogen, oxygen, nitrogen and vapor on both electrodes in the PEM fuel cell system are theoretically derived. These are chosen as five states; gas (moist hydrogen) in anode and gases (oxygen, nitrogen and vapor) in cathode, namely $\left[P_{\mathrm{H}_{2}} P_{\mathrm{H}_{2} \mathrm{O}_{\mathrm{A}}} P_{\mathrm{O}_{2}} P_{\mathrm{N}_{2}} P_{\mathrm{H}_{2} \mathrm{O}_{\mathrm{C}}}\right]$. The following assumptions are made to construct a model for PEM FC.

1-The amount of nitrogen in the cathode is constant whilst the required oxygen flow rate is determined by the nitrogen-oxygen flow ratio $(79 / 21)$.

2-The stack temperature is kept constant at $80^{\circ} \mathrm{C}[6,7]$.

2. 2. The Anode and Cathode Pressure Model According to the ideal gas principal and mole conservation rule, partial pressure of each gas is balanced by the gas inlet flow rate minus the gas consumption and the gas outlet flow rate as given by $[3$, 5-7]:

$\frac{d P_{H_{2}}}{d t}=\frac{R T}{V_{A}}\left(H_{2 \text { in }}-H_{2 \text { used }}-H_{2 \text { out }}\right)$

$\frac{d P_{\mathrm{H}^{2} \mathrm{O}_{A}}}{d t}=\frac{R T}{V_{A}}\left(\mathrm{H}_{2} \mathrm{O}_{\text {Ain }}-\mathrm{H}_{2} \mathrm{O}_{\mathrm{Aout}}-\mathrm{H}_{2} \mathrm{O}_{\text {mbr }}\right)$

where $\left[\mathrm{P}_{\mathrm{H}_{2}} \mathrm{P}_{\mathrm{H}_{2} \mathrm{O}_{\mathrm{A}}}\right]$ is partial pressure of hydrogen and water in the anode side respectively, ${ }_{2}$ in the inlet mass flow rate of hydrogen, $H_{2 \text { wed }}$ the reacted mass flow rate of hydrogen, $H_{2 \text { out }}$ the outlet flow rate of hydrogen, $\mathrm{H}_{2} \mathrm{O}_{\mathrm{A} \text { in }}$ the water mass flow rate into the anode, $\mathrm{H}_{2} \mathrm{O}_{\text {mbr }}$ the water flow rate across membrane, and $\mathrm{H}_{2} \mathrm{O}_{\mathrm{A} \text { out }}$ the purged water mass flow rate. State equations on the anode side are also given as:

$\frac{d P_{\mathrm{H}_{2}}}{d t}=\frac{R T}{V_{A}}\left[Y_{\mathrm{H}_{2}} U_{\mathrm{a}} K_{\mathrm{a}} \lambda_{\mathrm{H}_{2}}-\frac{N}{2 F} I_{\text {fc }}-\left(U_{\mathrm{a}} K_{\mathrm{a}} \lambda_{\mathrm{H}_{2}}-\frac{N}{2 F} I_{f c}\right) \frac{P_{\mathrm{H} 2}}{P_{\mathrm{H} 2}+P_{\mathrm{H} 2 \mathrm{OA}}}\right]$

$\frac{d P_{\mathrm{H}_{2} \mathrm{O}_{\mathrm{A}}}}{d t}=\frac{R T}{V_{\mathrm{A}}}\left[\left(\frac{\varphi_{\mathrm{a}} P_{v s}}{P_{\mathrm{H}_{2}}+P_{\mathrm{H}_{2} \mathrm{O}_{A}}-\varphi_{\mathrm{a}} P_{v s}} U_{\mathrm{a}} K_{\mathrm{a}} \lambda_{\mathrm{H}_{2}}\right.\right.$

$\left.\left.-\left(U_{\mathrm{a}} K_{\mathrm{a}} \lambda_{\mathrm{H}_{2}}-\mathrm{C}_{2} I_{\mathrm{fc}}\right) \frac{P_{\mathrm{H}_{2} \mathrm{O}_{\mathrm{A}}}}{P_{\mathrm{H}_{2}}+P_{\mathrm{H}_{2} \mathrm{O}}}-C_{2} I_{\text {fc }}\right)\right]$

Cathode mole conservation implies [3, 5-7]:

$$
\begin{aligned}
& \frac{d P_{\mathrm{O}_{2}}}{d t}=\frac{R T}{V_{C}}\left(O_{2 \text { in }}-O_{2 \text { used }}-O_{2 \text { out }}\right) \\
& \frac{d P_{\mathrm{N}_{2}}}{d t}=\frac{R T}{V_{C}}\left(N_{2 \text { in }}-N_{2 \text { out }}\right) \\
& \frac{d P_{\mathrm{H}_{2} \mathrm{O}_{\mathrm{C}}}}{d t}=\frac{R T}{V_{\mathrm{C}}}\left(\mathrm{H}_{2} \mathrm{O}_{\text {C in }}+\mathrm{H}_{2} \mathrm{O}_{C \text { produced }}-\mathrm{H}_{2} \mathrm{O}_{\text {Cout }}+\mathrm{H}_{2} \mathrm{O}_{\text {mbr }}\right)
\end{aligned}
$$


where $\left.{ }_{\left[P_{2}\right.} P_{\mathrm{N}_{2}} P_{\mathrm{H}_{2} \mathrm{O}_{\mathrm{C}}}\right]$ are partial pressures of oxygen, nitrogen and water in the cathode side respectively, $\left[O_{2 \text { in }} N_{2 \text { in }}\right]$ are inlet mass flow rate of oxygen and nitrogen into the cathode, $O_{2 \text { used }}$ is reacted mass flow rate of oxygen, $\left[O_{2 \text { out }} N_{2 \text { out }}\right]$ are outlet flow rate of oxygen and nitrogen, $\mathrm{H}_{2} \mathrm{O}_{\mathrm{C} \text { Produced }}$ is the reacted water mass flow rate, $\left[\mathrm{H}_{2} \mathrm{O}_{\mathrm{C} \text { in }} \mathrm{H}_{2} \mathrm{O}_{\mathrm{Cout}}\right]$ are the water mass flow rate into the cathode and out the cathode, $\mathrm{H}_{2} \mathrm{O}_{m b r}$ is the water flow rate across membrane. Similarly, state equations on the cathode side are expressed as:

$\frac{d P_{O_{2}}}{d t}=\frac{R T}{V_{C}}\left[Y_{O_{2}} U_{C} K_{C} \lambda_{\text {air }}-\frac{N}{4 F} I_{f c}-\left(U_{C} K_{C} \lambda_{\text {air }}-\frac{N}{4 F} I_{I_{c}}\right) \frac{P_{O_{2}}}{P_{O_{2}}+P_{N_{2}}+P_{H_{2} O_{C}}}\right]$

$\frac{d P_{N_{2}}}{d t}=\frac{R T}{V_{C}}\left[Y_{N_{2}} U_{C} K_{C} \lambda_{\text {air }}-\left(U_{C} K_{C} \lambda_{\text {air }}\right) \frac{P_{N_{2}}}{P_{O_{2}}+P_{N_{2}}+P_{H_{2} O_{C}}}\right]$

$\frac{d P_{\mathrm{H} 2 \mathrm{O}_{C}}}{d t}=\frac{R T}{V_{C}}\left(\frac{\varphi_{C} P_{v s}}{P_{\mathrm{O}_{2}}+P_{\mathrm{H}_{2} \mathrm{O}_{\mathrm{C}}}+P_{\mathrm{N}_{2}}-\varphi_{C} P_{v s}} U_{C} K_{C} \lambda_{\text {air }}+C_{1} I_{f c}\right.$

$\left.-\left(U_{C} K_{C} \lambda_{\text {air }}+C_{1} I_{f c}+C_{2} I_{f c}\right) \frac{P_{\mathrm{H}_{2} \mathrm{O}_{\mathrm{C}}}}{P_{\mathrm{O}_{2}}+P_{\mathrm{H}_{2} \mathrm{O}_{\mathrm{C}}}+P_{\mathrm{N}_{2}}}+C_{2} I_{\mathrm{fc}}\right)$

In the following a general MIMO nonlinear state space representation incorporating disturbance is developed:

$$
\begin{aligned}
& \dot{x}=f(x)+g_{1}(x) u_{1}+g_{2}(x) u_{2}+p(x) d \\
& y_{1}=h_{1}(x) \\
& y_{2}=h_{2}(x)
\end{aligned}
$$

$$
X=\left[\begin{array}{l}
X_{1} \\
X_{2} \\
X_{3} \\
X_{4} \\
X_{5}
\end{array}\right]=\left[\begin{array}{l}
P_{\mathrm{H}_{2}} \\
P_{\mathrm{H}_{2} \mathrm{O}_{\mathrm{A}}} \\
P_{\mathrm{O}_{2}} \\
P_{\mathrm{N}_{2}} \\
P_{\mathrm{H}_{2} \mathrm{O}_{\mathrm{C}}}
\end{array}\right], U=\left[\begin{array}{l}
U_{\mathrm{a}} \\
U_{C}
\end{array}\right],\left[\begin{array}{l}
y_{1} \\
y_{2}
\end{array}\right]=\left[\begin{array}{l}
X_{1} \\
X_{3}
\end{array}\right]=\left[\begin{array}{l}
h_{1}(x) \\
h_{2}(x)
\end{array}\right]=\left[\begin{array}{l}
P_{\mathrm{H}_{2}} \\
P_{\mathrm{O}_{2}}
\end{array}\right]
$$

where $x \in \mathbb{R}^{5}$ is the system state, $U$ the input vector, $y$ the output vector, and $f(x)$ and $g(x)$ are $n$-dimensional smooth vector fields. $d$ represents the disturbance variables whilst stack current is considered as a measurable disturbance $\left(d=I_{f c}\right)$. Vector $P(x)$ is coefficient of disturbance.

$$
f(x)=0, d=I_{f c}
$$

$$
g_{1}(x)=R T \lambda_{H_{2}}\left[\begin{array}{c}
\frac{k_{a} Y_{H_{2}}}{V_{A}}-\frac{k_{a}}{V_{A}} \frac{X_{1}}{X_{1}+X_{2}} \\
\frac{k_{a} \varphi_{a} P_{v s}}{V_{A}\left(X_{1}+X_{2}-\varphi_{a} P_{v s}\right)}-\frac{k_{a}}{V_{A}} \frac{X_{1}}{X_{1}+X_{2}} \\
0 \\
0
\end{array}\right]
$$

$$
g_{2}(x)=R T \lambda_{a i r}\left[\begin{array}{c}
0 \\
0 \\
\frac{k_{c} Y_{O_{2}}}{V_{C}}-\frac{k_{c}}{V_{C}} \frac{x_{3}}{x_{3}+x_{4}+x_{5}} \\
\frac{k_{c} Y_{N_{2}}}{V_{C}}-\frac{k_{c}}{V_{C}} \frac{x_{4}}{x_{3}+x_{4}+x_{5}} \\
\frac{k_{c} \varphi_{C} P_{v s}}{V_{C}\left(x_{3}+x_{4}+x_{5}-\varphi_{C} P_{v s}\right)}-\frac{k_{c}}{V_{C}} \frac{x_{5}}{x_{3}+x_{4}+x_{5}}
\end{array}\right]
$$

$$
P(x)=R T\left[\begin{array}{c}
-\frac{C_{1}}{V_{A}}+\frac{C_{1} x_{1}}{V_{A}\left(x_{1}+x_{2}\right)} \\
\frac{C_{2} x_{2}}{V_{A}\left(x_{1}+x_{2}\right)}-\frac{C_{2}}{V_{A}} \\
-\frac{C_{1}}{2 V_{C}}+\frac{C_{1} x_{3}}{2 V_{C}\left(x_{3}+x_{4}+x_{5}\right)} \\
\frac{0}{C_{1}}-\frac{C_{1} x_{5}}{V_{C}}-\frac{C_{2} x_{5}}{V_{C}\left(x_{3}+x_{4}+x_{5}\right)}+\frac{C_{2}}{V_{C}\left(x_{3}+x_{4}+x_{5}\right)}
\end{array}\right]
$$

\section{BASIC CONCEPTS OF HIGH ORDER SLIDING MODE CONTROL}

This technique is used to provide a robust control under uncertainties in parameters and unknown perturbations. The first step in SMC is to define a sliding surface $S(t)$ such that the process slides to its desired value. In fact, the sliding surface represents the system behavior during the transient period. In the standard SMC, term $\dot{S}(t)$ is discontinuous. This is the main reason why high frequency switching appears in the output signal (chattering effect). In order to avoid chattering, a high order sliding mode control (HOSMC) may be used [17, 19-21]. HOSMC acts in terms of higher order time derivative of the system, instead of using a first derivative of deviation as in SMC.

3. 1. Control Objective and Sliding Surface The first stage to design a nonlinear SOSM based control system is to reformulate the model according to the requirements of the SOSM design procedure. A control objective will be established and accordingly a sliding surface is defined in second stage. The objective is to control hydrogen and oxygen partial pressures to avoid unwanted pressure fluctuations. This protects MEA from collapsing by minimizing the pressure drop $\Delta P$, between the anode and the cathode, even under different load conditions. The control objective is expressed as follows:

$S_{1}(x, t)=P_{H_{2}}-P_{H_{2} \text { ref }} \quad, \quad S_{2}(x, t)=P_{\mathrm{O}_{2}}-P_{\mathrm{O}_{2} \text { ref }}$

where $S_{1}(x, t)$ and $S_{2}(x, t)$ are the sliding variables that must be steered to zero and $P_{\mathrm{H}_{2} \text { ref }}, P_{\mathrm{O}_{2} \text { ref }}$ are the hydrogen partial pressure and oxygen partial pressure reference, respectively. The sliding variable $S$ has a 
vector of relative degree of one with respect to the control input $u$. Consider a single-input single-output nonlinear system:

$\dot{x}=f(x)+g(x) \cdot u, y=S(x, t)$

where $x \in{ }^{n}$ as state variable and $u \in$ denotes input, such that $\left\{\left|x_{i}\right|<x_{i, M A X}, 1 \leq i \leq n\right\} \quad$ and $\quad\left\{|u| \leq u_{M A X}\right\}$. Functions $f, g$ are smooth uncertain functions, $S(x, t)$ is an output function or sliding variable.

3. 1. 1. Definition 1. $[22,23]$ Given the sliding variable $S(x, t)$, its "second order sliding manifold" is defined by:

$S^{2}=\{S(x, t)=\dot{S}(x, t)=0\}$

In order to establish sliding mode on this manifold, a control problem is to force $S(x, t)$ and $\dot{S}(x, t)$ to zero, by applying a discontinuous control on $\ddot{S}(x, t)$. Since the relative degree is found one with respect to the sliding variable, they are expressed as:

$\dot{S}=\frac{\partial}{\partial x}[S] \cdot[f(x)+g(x) \cdot u]$

$\ddot{S}=\frac{\partial}{\partial x}[\dot{S}] \cdot[f(x)+g(x) \cdot u]+\frac{\partial}{\partial u}[\dot{S}] \cdot \dot{u}=\varphi(x, u, t)+\gamma(x, u, t) \cdot v$

where discontinuous control is applied on $v=u$, while system (17) is controlled by $u \cdot \varphi(x, u, t)$ and $\gamma(x, u, t)$ for the PEMFC systems are smooth functions to force $S$ to zero in finite time. It is also supposed that:

$\varphi>0, \quad|\varphi(t, x, u)| \leq C_{0}, 0<\Gamma_{m} \leq \gamma(t, x, u) \leq \Gamma_{M}$.

According to local coordinate $\left[\delta_{1}, \delta_{2}\right]^{T}=[S, \dot{S}]^{T}$ then a second order sliding mode problem in (20) becomes finite time stabile for the following uncertain second order system:

$$
\begin{aligned}
& \dot{\delta}_{1}=\delta_{2} \\
& \dot{\delta}_{2}=\varphi(x, u, t)+\gamma(x, u, t) . V
\end{aligned}
$$

\section{2. Twisting Algorithm}

There are several algorithms which ensure finite time stabilization of system (21). Twisting algorithm [19, 22, 24] belongs to class of second order sliding mode when the relative degree is two. This means that trajectories $S$ and $\dot{S}$ converge to the origin in finite number of rotations. This algorithm is defined by the following control law $[19,22,24]$, where $u_{\max }$ is an allowable maximum value of $u$ :

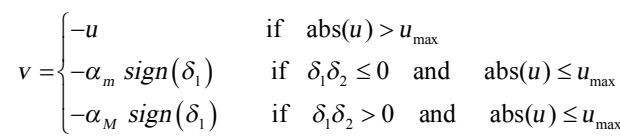

Corresponding, sufficient conditions to achieve a finite time convergence to the sliding manifold $S$ is given by Levant 1993 [22] as:

$0<\alpha_{m}<\alpha_{M}, \quad \alpha_{m}>\frac{C}{K_{m}} \quad K_{m} . \alpha_{M}-C>K_{M} . \alpha_{m}+C$
It is seen that control law (22) needs information of $\left[\delta_{1}, \delta_{2}\right]^{T}=[S, \dot{S}]^{T}$ which requires information about the time derivative of the sliding manifold $S$.

\section{STEP BY STEP SUPER TWISTING DIFFERENTIATOR}

In order to implement the controller in (22), a first time derivative of output error (sliding surface) is required. However, it can be estimated in a finite time by using a second order universal sliding differentiator. A first kind of robust discontinuous differentiators is extensively investigated [16, 17]. Levant in 1998 and 2003 showed that the super twisting differentiator is robust and accurate and a finite time convergent one. The idea behind the routine designed differentiator was first introduced by Usai et al. [18]. An algebraic observability was used to synchronize chaos by using a suboptimal algorithm. As a restriction, this algorithm needs a peak holder which is hard in implementation. Furthermore, the algorithm offers no estimation of the convergence time. However, the differentiator will be developed here based on super twisting algorithm for the first time. The idea includes a single super twisting based differentiator to generate successive derivatives of $f(t)$ signals in $n-1$ steps (Figure 2). Main advantage of this design is a real-time and robust estimation of $\dot{f}(t), \ddot{f}(t), \ldots$ and $f^{(n)}(t)$ made available. Functions $x_{1}=f(t), \quad \dot{x}_{1}=\dot{f}(t), \quad \dot{x}_{2}=\ddot{f}(t) \quad$ to $\quad \dot{x}_{n}=f^{(n)}(t)$ are base signals of $f(t)$ for $n$ steps of differentiation according to Equation (24). An aim is here to estimate signals $\dot{f}(t), \ddot{f}(t), \ldots$ and $f^{(n)}(t)$ after a finite and predetermined time.

$$
\left\{\begin{array}{l}
\dot{x}_{1}=x_{2}=\dot{f}(t) \\
\dot{x}_{2}=x_{3}=\ddot{f}(t) \\
\vdots \\
\dot{x}_{n-1}=x_{n}=f^{(n-1)}(t) \\
\dot{x}_{n}=f^{(n)}(t)
\end{array}\right.
$$

This technique uses super twisting algorithm together with some extra injection terms as in the following form:

$$
\begin{aligned}
& {\left[\begin{array}{l}
\dot{\hat{x}}_{1} \\
\dot{\hat{x}}_{2} \\
\vdots \\
\dot{\hat{x}}_{n-1} \\
\dot{\hat{x}}_{n}
\end{array}\right]=\left[\begin{array}{l}
\tilde{x}_{2}+\lambda_{1}\left|x_{1}-\hat{x}_{1}\right|^{\frac{1}{2}} \operatorname{sign}\left(x_{1}-\hat{x}_{1}\right) \\
E_{1} \cdot\left[\tilde{x}_{3}+\lambda_{2}\left|\tilde{x}_{2}-\hat{x}_{2}\right|^{\frac{1}{2}} \operatorname{sign}\left(\tilde{x}_{2}-\hat{x}_{2}\right)\right] \\
\vdots \\
E_{n-2}\left[\tilde{x}_{n}+\lambda_{n-1}\left|\tilde{x}_{n-1}-\hat{x}_{n-1}\right|^{\frac{1}{2}} \operatorname{sign}\left(\tilde{x}_{n-1}-\hat{x}_{n-1}\right)\right] \\
E_{n-1}\left[\tilde{\theta}+\lambda_{n}\left|\tilde{x}_{n}-\hat{x}_{n}\right|^{\frac{1}{2}} \operatorname{sign}\left(\tilde{x}_{n}-\hat{x}_{n}\right)\right]
\end{array}\right]} \\
& \Rightarrow\left[\begin{array}{l}
\dot{\hat{x}}_{1} \\
\dot{\hat{x}}_{2} \\
\vdots \\
\dot{\hat{x}}_{n-1} \\
\dot{\hat{x}}_{n}
\end{array}\right]=\left[\begin{array}{l}
\tilde{x}_{2}+\varphi_{1}\left(e_{1}\right) \\
E_{1} \cdot\left[\tilde{x}_{3}+\varphi_{1}\left(e_{2}\right)\right] \\
\vdots \\
E_{n-2} \cdot\left[\tilde{x}_{n}+\varphi_{1}\left(e_{n-1}\right)\right] \\
E_{n-1} \cdot\left[\tilde{\theta}+\varphi_{1}\left(e_{n}\right)\right]
\end{array}\right]
\end{aligned}
$$

In Equation (25), $E_{i}$ is: 
- if $E_{i}=1$ then $\left|e_{j}\right|=\left|\tilde{X}_{j}-\hat{x}_{j}\right| \leq \epsilon$

- if $E_{i}=0$ then $\left|e_{j}\right|=\left|\tilde{x}_{j}-\hat{x}_{j}\right|>\epsilon$

where $\in$ is a small positive constant. It should be noted that $E_{i}=0$ indicates the error of that step is not converging either $\in$ or zero. Therefore, jumping to the next step to estimate next signal is not taken. Alternatively, if $E_{i}=1$, the estimation error of the signal in that step reaches zero or $\in$. Therefore, the process proceeds to the next step for estimating the next signal. In addition to proving stability through Lyapunov function, additional terms are added to differentiators to provide faster finite time. It will be shown that convergence time is limited by a constant. These terms are defined in functions of $\varphi_{1}\left(e_{1}\right)$ and $\varphi_{2}\left(e_{1}\right)$ of differentiator in (25). This is summarized in the following form to indicate systematic procedure of designing the differentiator with linear terms for improving the convergence rate:

$$
\begin{aligned}
& \left\{\begin{array}{l}
\dot{\hat{x}}_{1}=\tilde{x}_{2}+k_{1} \varphi_{1}\left(\mathrm{e}_{1}\right) \\
\dot{\tilde{x}}_{2}=k_{2} \varphi_{2}\left(\mathrm{e}_{1}\right)
\end{array}\right. \\
& \left\{\begin{array}{l}
\varphi_{1}\left(\mathrm{e}_{1}\right)=\left|\mathrm{e}_{1}\right|^{\frac{1}{2}} \cdot \operatorname{sign}\left(\mathrm{e}_{1}\right)+\mu \cdot \mathrm{e}_{1} \\
\varphi_{2}\left(\mathrm{e}_{1}\right)=\frac{\operatorname{sign}\left(\mathrm{e}_{1}\right)}{2}+\mu^{2} \cdot \mathrm{e}_{1}+\frac{3}{2} \mu \cdot\left|\mathrm{e}_{1}\right|^{\frac{1}{2}} \cdot \operatorname{sign}\left(\mathrm{e}_{1}\right)
\end{array}\right.
\end{aligned}
$$

By adding these linear terms in case $X$ is far from the origin, a more powerful force for attracting estimation signals to the origin is generated. These terms work well when the state $X$ is far from its estimated value (the equilibrium points for the error). For $\mu>0$ super twisting path converges to origin from $x_{0}$ after a finite time $T$. In case these accelerating terms are added to the super twisting algorithm, error dynamic equation becomes:

$$
\begin{aligned}
& \left\{\begin{array}{l}
\dot{\mathrm{e}}_{1}=-k_{1} \cdot \varphi_{1}\left(\mathrm{e}_{1}\right)+\mathrm{e}_{2} \\
\dot{\mathrm{e}}_{2}=-k_{2} \cdot \varphi_{2}\left(\mathrm{e}_{1}\right)-\dot{\varsigma}_{1}
\end{array}\right. \\
& \mathrm{e}_{1}=\hat{x}_{1}-f(t), \mathrm{e}_{2}=\tilde{x}_{2}-\varsigma_{1} \\
& \varsigma_{0}=f(t), \quad \dot{\zeta}_{0}=\dot{f}(t), \quad \dot{\zeta}_{1}=\ddot{f}(t), \quad|\ddot{f}(t)|<L \\
& \left\{\begin{array}{l}
\varphi_{1}\left(\mathrm{e}_{1}\right)=\left|\mathrm{e}_{1}\right|^{\frac{1}{2}} \cdot \operatorname{sign}\left(\mathrm{e}_{1}\right)+\mu \cdot \mathrm{e}_{1} \\
\varphi_{2}\left(\mathrm{e}_{1}\right)=\frac{\operatorname{sign}\left(\mathrm{e}_{1}\right)}{2}+\mu^{2} \cdot \mathrm{e}_{1}+\frac{3}{2} \mu \cdot\left|\mathrm{e}_{1}\right|^{\frac{1}{2}} \cdot \operatorname{sign}\left(\mathrm{e}_{1}\right)
\end{array}\right.
\end{aligned}
$$

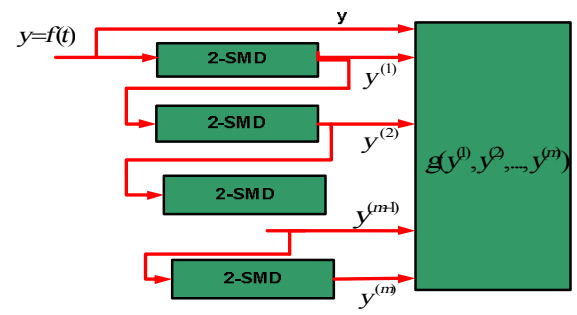

Figure 2. Step by step differentiator based on super twisting algorithm
4. 2. Proof of Finite Time Convergence using the Proposed Differentiator Two Lyapunov functions are candidate to achieve a uniform convergent when the differentiator is used in the super twisting algorithm.

- Another function to converge in a finite time from any compact set towards the origin in any path [Moreno].

- A Lyapunov function to converge in a finite time from any arbitrary initial conditions into a compact set including the origin.

A linear method to derive the Lyapunov function is primarily proposed by Moreno in 2008 and 2009 [9, 10]. In this regard the time of convergence i.e. $T_{f . t 1}$ is found by (29) to achieve the first derivative of $f_{0}(t)$. However, in order to find time of providing the second derivative $\ddot{f}(t)$ and appropriate time of convergence i.e. $T_{f . t 2}$ another design of Lyapunov is needed. This algorithm is proceeded until total time of convergence of an n-order differentiator i.e. $T_{f . t 1}, T_{f . t 2}, \ldots$ and $T_{f . t n}$ is achieved. Since the whole time for the differentiator is limited by summation of those, finite time of convergence is determined.

Theorem 1. [Moreno 25, 26] Super twisting algorithm including additional terms in (27) and (28), initiating from $X_{0}$ in a finite time $T_{f . t 1}$ converges to the origin.

It should be noted that the time is assessed in the following considering two cases $\mu=0$ as a STA and $\mu=1$ as STA together with additional terms:

$T_{f . t 1}= \begin{cases}\frac{2}{\gamma_{1}(Q)} V^{\frac{1}{2}}\left(x_{0}\right) & \text { if } \mu=0 \\ \frac{2}{\gamma_{2}(Q, \mu)} \ln \left(\frac{\gamma_{2}(Q, \mu)}{\gamma_{1}(Q)} V^{\frac{1}{2}}\left(x_{0}\right)+1\right) & \text { if } \mu>0\end{cases}$

$\gamma_{1}(Q)=\frac{\lambda_{\min }\{Q\} \lambda_{\min }^{0.5}\{P\}}{2 \lambda_{\max }\{P\}}, \gamma_{2}(Q, \mu)=\mu \frac{\lambda_{\min }\{Q\}}{\lambda_{\max }\{P\}}$

Theorem 2. Lyapunov function for Equations (27) and (28) considering additional terms is presented in (30) to ensure a uniform convergence of system (27) and (28) in total time of convergence $T_{u f}$ as in (31).

$$
\begin{aligned}
& V_{2}(\mathrm{e})=\frac{\sigma}{2} \cdot k_{2} \cdot\left|\mathrm{e}_{1}\right|^{2}-\mathrm{e}_{1} \cdot\left|\mathrm{e}_{2}\right| \cdot \operatorname{sign}\left(\mathrm{e}_{2}\right)+\frac{\sigma}{2} \cdot\left|\mathrm{e}_{2}\right|^{2} \\
& v(t) \leq v(0) \cdot \exp \left(-\frac{C_{1}}{2 \cdot C_{4}} \cdot t\right) \Rightarrow-\frac{2 \cdot C_{4}}{C_{1}} \cdot \ln \left(\frac{\varepsilon}{V_{0}}\right)=T_{u \cdot f}\left(\varepsilon, V_{0}\right) \\
& V_{f}=\varepsilon
\end{aligned}
$$

Total convergence time $\left(T=T_{u f}+T_{f t}\right)$ is equal the convergence time $_{\left(T_{u f}\right)}$ to reach from any arbitrary initial condition to a compact set and a convergence time $\left(T_{f t}\right)$ within the compact set. As seen in Figure 3, Equation (30) is always convex. Accordingly, it will be 
shown that function $V_{2}(e)$ is positive definite and the derivative of $V_{2}(e)$ is negative definite (see Appendix A).

4. 2. Determination of Convergence Time, the $\mathrm{N}$ Step Super Twisting Differentiator Systematic design finite time convergent differentiator will be achieved as in the following:

First step $\left(\dot{e}_{1}=e_{2}, e_{1}\right) \rightarrow(0,0)$ in a finite time of $T_{1}$. In second step $\left(\dot{e}_{2}=e_{3}, e_{2}\right) \rightarrow(0,0)$; therefore, second differentiation tends to the real one in a finite time of $T_{2}$. Until ith step: $\left(\dot{e}_{i}=e_{i+1}, e_{i}\right) \rightarrow(0,0)$, and the convergence of the differentiation to the real signal is achieved in $T_{i}$. Finally at (n-1)th step: $\left(\dot{e}_{n-1}=e_{n}, e_{n-1}\right) \rightarrow(0,0)$, and the convergence is achieved in $T_{n-1}$. Accordingly, total time of convergence is achieved by a summation over the entire achieved time, i.e. $T=\sum_{i=1}^{n-1} T_{i}$.

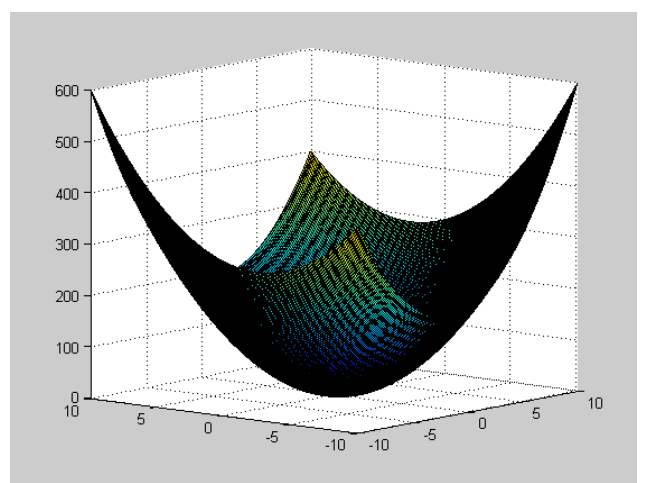

Figure 3. Behavior of the Lyapunov candidate

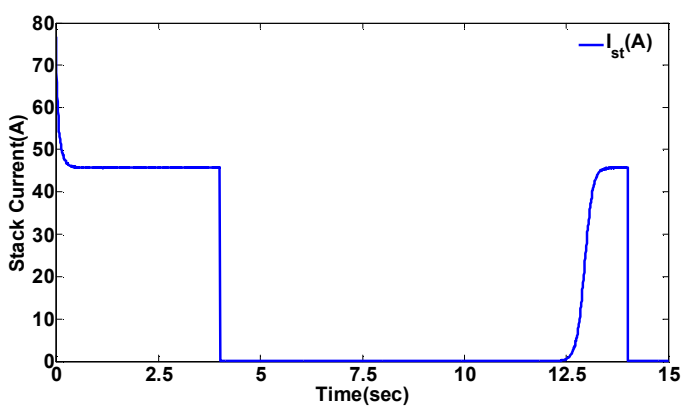

Figure 4. Load current variation profile

\section{SIMULATION RESULTS}

To verify the performance of the proposed control law (22) in presence of model uncertainties, external disturbances against in a wide range of current demand several simulations studies are performed in MATLAB $^{\mathrm{TM}}$-Simulink environment. During the simulation the temperature and the humidity of the system are kept constant and $\mu=1$ is set for the differentiator. The rest of parameters are tuned according to Table 1 . The load disturbance is subjected to a variation of current from $0 \mathrm{~A}$ to $47 \mathrm{~A}$ as shown in Figure 4. Figures 5 and 6 display an absolute value of the difference between partial pressures of hydrogen and oxygen. Figure 5 uses a first order SMC to regulate pressure difference of $\mathrm{O}_{2}$ and $\mathrm{H}_{2}$ whilst Figure 6 successfully gains the benefit of the twisting algorithm in combination with the prescribed differentiator. From these graphs one can see that the second order sliding mode (SOSM) controller with differentiator in Figure 6 provides better response in terms of time indices, and of course, chattering. The achieved results are addressed in the following.

TABLE 1. Parameters in the fuel cell model

\begin{tabular}{|c|c|}
\hline Parameter & Value and definition \\
\hline$N$ & Cell number :35 \\
\hline$R$ & Universal gas constant $[\mathrm{J} / \mathrm{mol}-\mathrm{k}]: 8.314[\mathrm{~J} / \mathrm{mol}-\mathrm{K}]$ \\
\hline$T$ & Temperature of fuel cell[K]: $353[\mathrm{~K}]$ \\
\hline$F$ & Faraday constant $[\mathrm{C} / \mathrm{mole}]: 96485[\mathrm{C} / \mathrm{mole}]$ \\
\hline$\alpha$ & Charge transfer coefficient: 0.5 \\
\hline$m$ & Constant in mass transfer voltage: $2.11 \times 10^{-5}[\mathrm{~V}]$ \\
\hline$n$ & Constant in mass transfer voltage: $8 \times 10^{-3}\left[\mathrm{~cm}^{2} \mathrm{~mA}^{-1}\right]$ \\
\hline$r$ & Area specific resistance: $2.45 \times 10^{-4}\left[\mathrm{~K} \Omega \mathrm{cm}^{2}\right]$ \\
\hline$A_{f c}$ & Fuel cell active area: $232\left[\mathrm{~cm}^{2}\right]$ \\
\hline$V_{A}$ & Anode volume: $0.005_{\left[\mathrm{m}^{3}\right]}$ \\
\hline$V_{C}$ & Cathode volume: $0.01\left[\mathrm{~m}^{3}\right]$ \\
\hline$k_{a}$ & Anode conversion factor : $7.034 \times 10^{-4}[\mathrm{~mol} / \mathrm{s}]$ \\
\hline$k_{c}$ & Cathode conversion factor : $7.036 \times 10^{-4}[\mathrm{~mol} / \mathrm{s}]$ \\
\hline$P_{V S}$ & $\begin{array}{l}\text { The saturation pressure at the temperature } 353[\mathrm{~K}] \text { : } \\
32[\mathrm{KPa}]\end{array}$ \\
\hline $\mathrm{Y}_{2}$ & Oxygen initial mole fraction : 0.21 \\
\hline$Y_{H_{2}}$ & Hydrogen initial mole fraction : 0.99 \\
\hline$Y_{N_{2}}$ & Nitrogen initial mole fraction : 0.79 \\
\hline$\varphi_{c}$ & The relative humidity on cathode \\
\hline$\varphi_{a}$ & The relative humidity on anode \\
\hline$\lambda_{\text {air }}$ & Air stoichiometry \\
\hline$\lambda_{\mathrm{H}_{2}}$ & Hydrogen stoichiometry \\
\hline$U_{\mathrm{a}}$ & Control input in anode side \\
\hline$U_{C}$ & Control input in cathode side \\
\hline$C_{1}=\frac{N A_{f c}}{2 F}$ & $C_{2}=1.2684 \cdot \frac{N A_{f c}}{F}$ \\
\hline
\end{tabular}




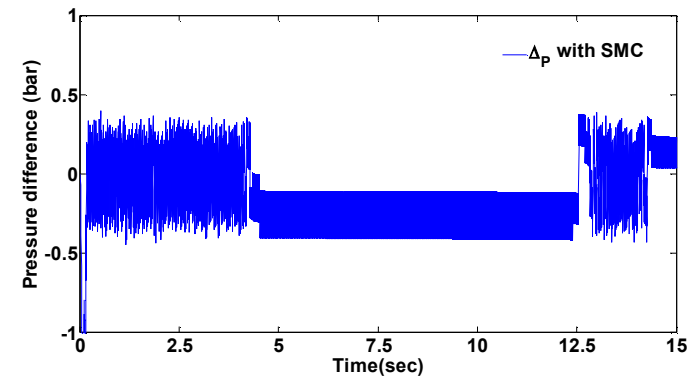

Figure 5. Variation of the pressure difference of $\mathrm{O}_{2}$ and $\mathrm{H}_{2}$ using a first order sliding mode controller

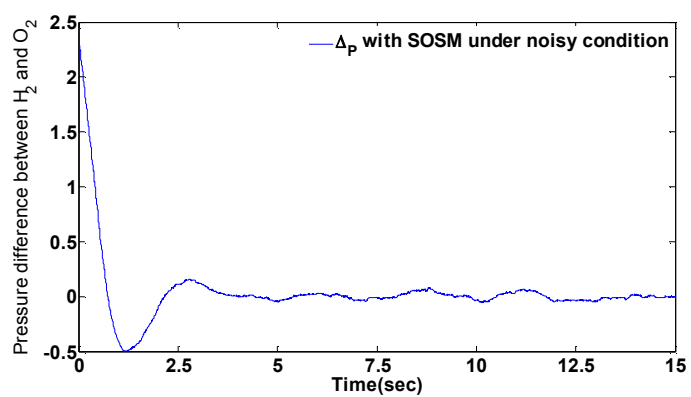

Figure 6. Variation of the inlet pressure difference of $\mathrm{O}_{2}$ and $\mathrm{H}_{2}$ using SOSM controller with differentiator

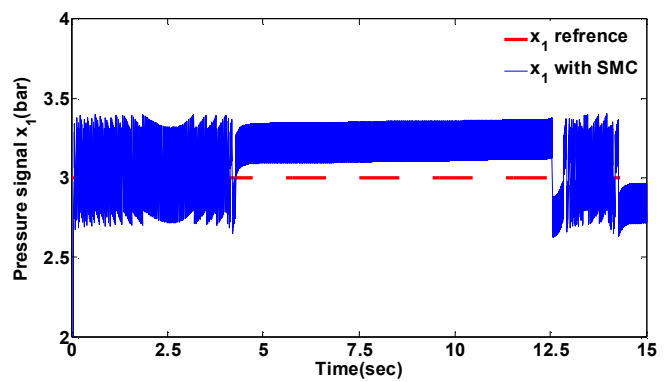

Figure 7. Inlet hydrogen pressure with respect to desired level (3 bar) using SMC controller

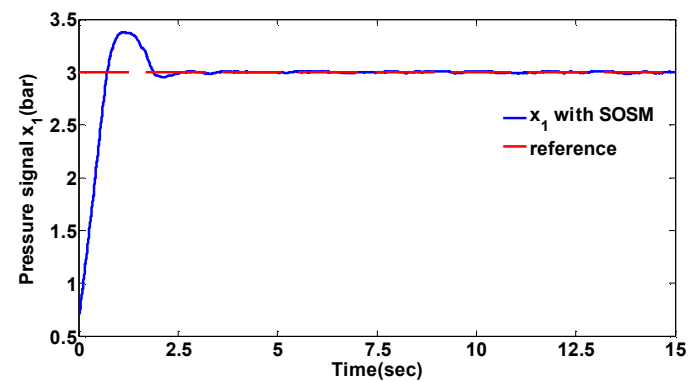

Figure 8. Inlet hydrogen pressure with respect to desired level (3bar) using SOSM controller with differentiator

5. 1. Chattering Analysis The second order sliding mode controller provides similar robustness and performance with respect to SMC (First order or standard sliding mode), but without chattering. Unfortunately, the inlet pressure difference of $\mathrm{O}_{2}$ and $\mathrm{H}_{2}$ in Figure 5 shows chattering with high frequency which is usually harmful to physical systems. In contrast, the second order sliding mode with differentiator attenuated the chattering phenomenon (Figure 6).

5. 2. Tracking Analysis Trajectories tracking of inlet oxygen pressure in response to the reference pressure are shown in Figures 7 and 8 using SMC and SOSM controller with differentiator, respectively. Results are found encouraging due to narrow band of the error in Figure 8.

Figures 9 and 10 show the required control signals against the load variations which are generated by SMC and SOSM controller with differentiator respectively. The hydrogen flow rate using SMC varies between 0 [slpm] to 15 [slpm], while the input signal in the second controller causes the hydrogen flow rate to vary from 0 [slpm] to 3.5 [slpm]. It is observed that the hydrogen flow rate in SMC has much more variations. Furthermore, hydrogen consumption is more than that in the case of the SOSM controller against the load variation.

Figures in 11 show derivatives of the error during estimations procedure, i.e. $S, \dot{S}$ using the proposed differentiator. It is shown that the convergence speed of estimation of the differentiator $S, \dot{S}$ is provided in a finite time of less than 0.24 second.

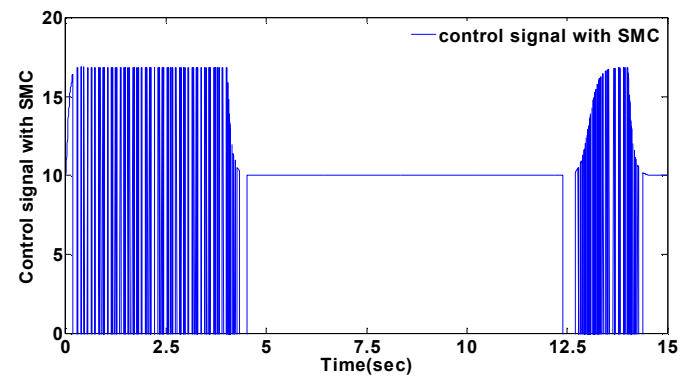

Figure 9. Control signal using SMC

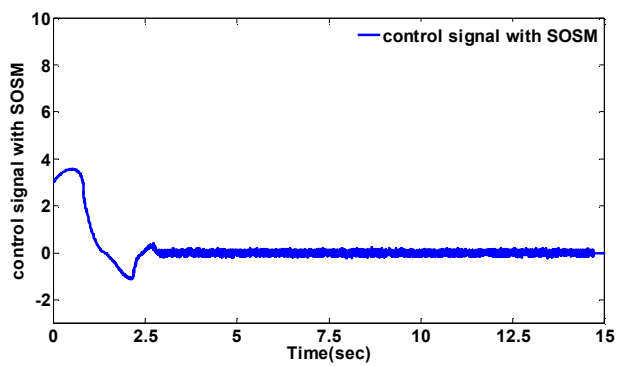

Figure 10. Control signal which is provided by SOSM controller with differentiator 

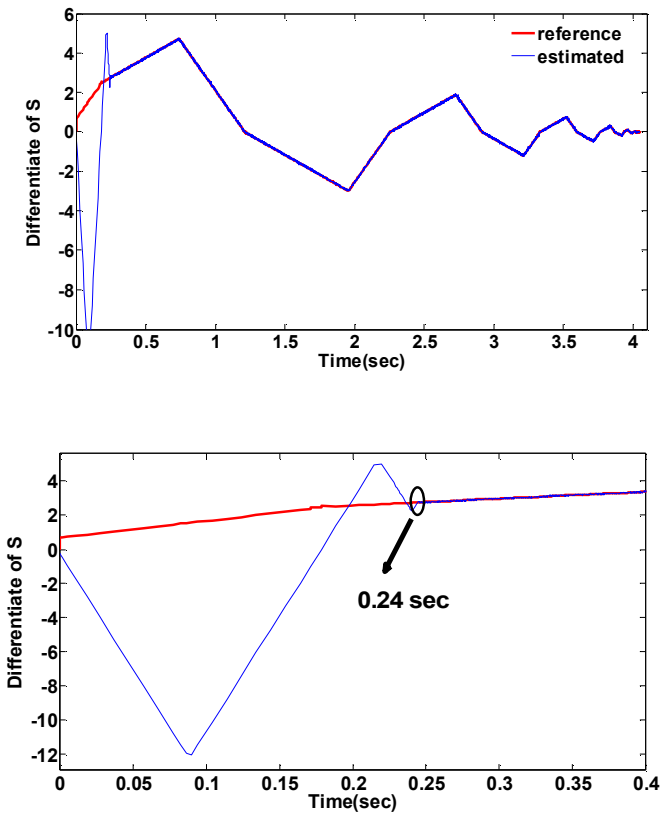

Figure 11. Estimations of $S$ differentiate with step by step differentiator

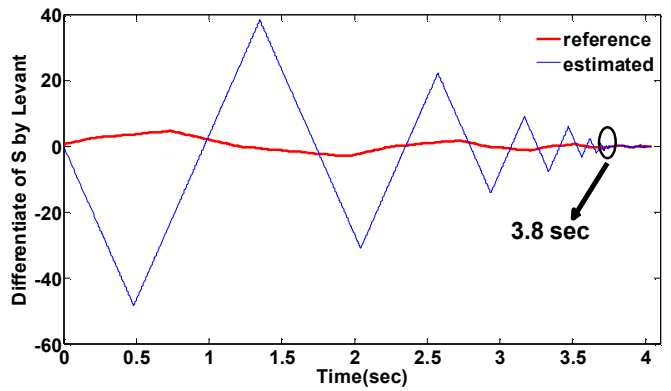

Figure 12. Estimations of the surface differentiation by the Levant differentiator

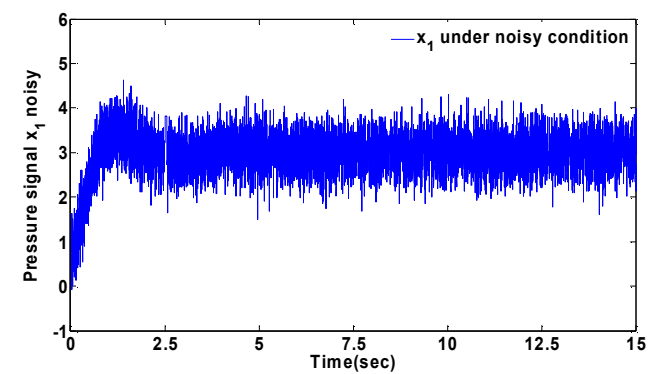

Figure 13. The $\mathrm{H}_{2}$ pressure signal of under noisy circumstance

5. 3. Comparative Study of Super Twisting and the Levant Differentiator Performance of the proposed super twisting differentiator will be compared with that of the Levant in terms of the time indices. The convergence time of using the proposed differentiator is fast as shown in Figure 11 i.e. 0.24 second with respect to 3.8 seconds in the Levant's (Figure 12). Two linear terms are added to the super twisting algorithm to provide more convergence time together with more robustness. This extra degree of freedom provides a strong attraction force when states are far from the origin. The further from the origin, the more forces are acted by the added terms. Therefore, fast convergence together with further robustness for wider range of uncertainty is provided.

\section{4. Pressure Control using SOSM Controller with} Differentiator and Feedback Linearization Technique under Noisy Circumstances: a Comparative Study In order to investigate the capability of the proposed configuration, a practical instrumentation noise is added to the measurement. Characteristic of the noisy data is seen in the following table.

These noisy data are applied to states of hydrogen pressure $\left(\mathrm{x}_{1}\right)$, and oxygen pressure $\left(\mathrm{x}_{3}\right)$. Before simulation and as a practical treatment, data are passed through a low pass 2 nd-order Butterworth filter with 30 $\mathrm{Hz}$ cut off frequency. Thereafter, hydrogen pressure $\left(\mathrm{x}_{1}\right)$ is seen under noisy circumstances in Figure 13. The outcome of using feedback linearization (Figure 14) is compared with SOSM based twisting algorithm with differentiator (Figure 15). From these graphs, performance of the proposed controller SOSM controller with differentiator is found satisfactory in presence of noisy data. However, the SOSM controller is more robust with respect to the feedback linearization against the noise in the tracking duty.

TABLE 2. Statistics of the applied measurement noise

\begin{tabular}{lll}
$\begin{array}{l}\text { Mean } \\
=0.0023237\end{array}$ & Variance $=0.13362$ & Co-variance $=0.0179$ \\
\hline PSD $=0.22$ & $\begin{array}{l}\text { Signal/Noise(SNR) } \\
=28 \mathrm{~dB}\end{array}$ & $\begin{array}{l}\text { The Distribution: } \\
\text { Gaussian }\end{array}$ \\
\hline
\end{tabular}

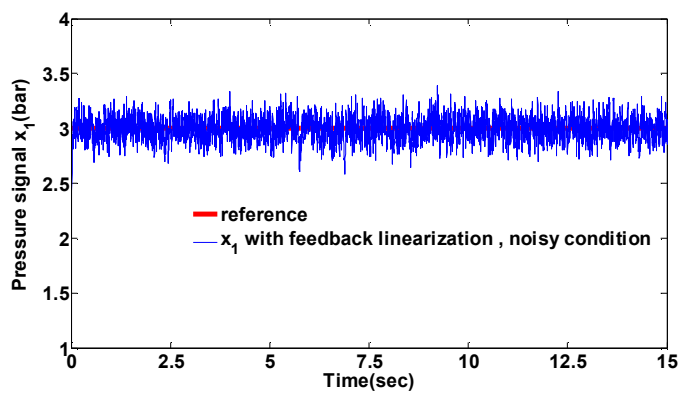

Figure 14. The $\mathrm{H}_{2}$ pressure control under noisy situation using feedback linearization technique 


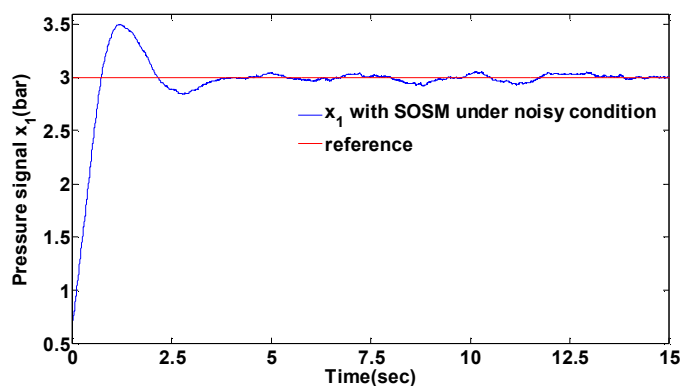

Figure 15. The $\mathrm{H}_{2}$ pressure control under noisy situation using SOSM controller with differentiator

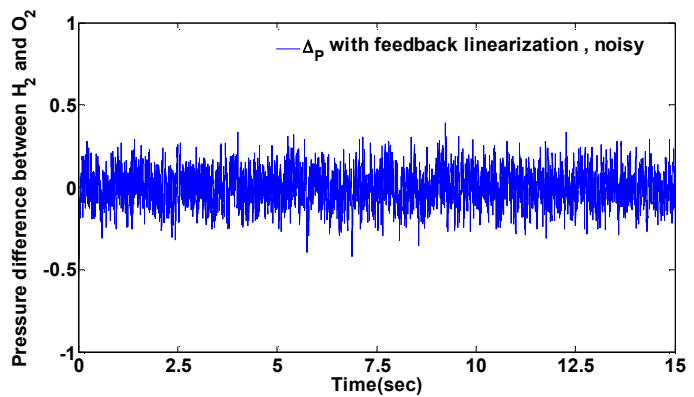

Figure 16. Variation of the pressure difference of $\mathrm{O}_{2}$ and $\mathrm{H}_{2}$ under noisy situation using feedback linearization technique

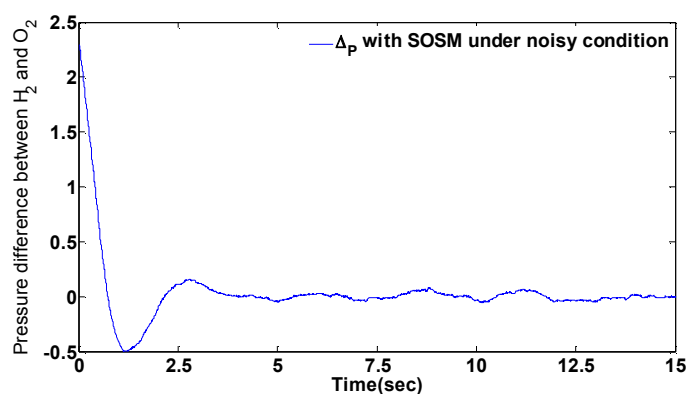

Figure 17. Variation of the pressure difference of $\mathrm{O}_{2}$ and $\mathrm{H}_{2}$ under noisy situation using SOSM controller with differentiator

In the following, control pressure difference $\left(\Delta \mathrm{P}\right.$ of $\mathrm{x}_{1}$ and $\mathrm{x}_{3}$ ) of oxygen and hydrogen using two techniques of feedback linearization and SOSM will be shown. Similar results are achieved confirming performance of the SOSM with respect to the feedback linearization when lower pressure oscillations are acted on two sides of MEA.

\section{CONCLUSION}

High order sliding mode controller keeps $\Delta P$ in a lower range to protect the membrane from damage. Therefore, it prolongs the life of the fuel cell stack. A pressure control technique for PEMFC was designed in this paper. An analytical study is given to proof the validity of the finite time convergence. Significance of the proposed controller is shown through numerical simulation. Performance of the control is also investigated in presence of external disturbance. Super Twisting algorithm is found to have the following advantages:

- It guarantees an extended range of operation, in spite of the highly nonlinear nature of the plant.

- Robust against chattering.

- Structure of the algorithm is routine and feasible.

Furthermore, a differentiator was introduced to provide a finite time convergence. This permits the controller to take part quickly, as soon as the differentiator reconstructs the necessary state(s). Performance of the super twisting algorithm and also with combination of the proposed differentiator is shown through simulation.

\section{REFERENCES}

1. Larminie, J., Dicks, A., "Fuel cell systems explained", 2nd ed. New York, USA, Wiley \& Sons, (2003).

2. Chiu, L.Y., Diong, B. andGemmen, R.S., "An Improved Small Signal Model of the Dynamic Behavior of PEM Fuel Cells", IEEE Transactions on Industry Application, Vol. 40, (2004), 970-977.

3. Peng, H. and Pukrushpan, J.,"Control of Fuel Cell Power Systems: Principle, Modeling, Analysis and Feedback Design", Berlin, Germany Springers-Verlag, (2004).

4. Pukrushpan, J., Peng, H. and Stefanopoulou, A., "Simulation and analysis of transient fuel cell system Performance based on a dynamic reactant flow model", In: Proceedings of IMECE'02 ASME International Mechanical Engineering Congress \& Exposition, New Orleans, Louisiana, USA, (2002), 1-12.

5. Pukrushpan,J., Stefanopoulou, A. and Peng, H.,"Control of Fuel Cell Breathing", Control Systems Magazine, Vol. 24, (2004), $30-46$.

6. Na,W. K., Gou,B. and Diong, B.,"Nonlinear Control of PEM Fuel Cells by Exact Linearization", IEEE Transactions on Industry Application, Vol. 43, (2007), 1426-1433.

7. Na,W.K., Gou,B., "Feedback-Linearization-Based Nonlinear Control for PEM Fuel Cells", IEEE Transactions on Energy Conversion, Vol. 23, (2008), 179-190.

8. Li, Q., Chen, W., Wang, Y., Jia, J. and Han, M., "Nonlinear robust control of proton exchange membrane fuel cell by state feedback exact linearization", Journal of Power Sources, Vol. 194, (2009), 338-348.

9. Garcia-Gabin, W., Dorado, F. and Bordons, C., "Real-time implementation of a sliding mode controller for air supply on a PEM fuel cell", Journal of Process Control, Vol. 20, (2010), 325-336.

10. Talj, R.J., Hissel, D., Ortega, R., Becherif, M. and Hilairet, M., "Experimental Validation of a PEM Fuel Cell Reduced Order Model and a Moto-Compressor Higher Order Sliding Mode Control", IEEE Transactions on Industrial Electronics, Vol. 57,(2010), 1906-1913.

11. Talj, R.J., Hissel, D., Ortega, R., Becherif, M. and Hilairet, M.,"Reduced-Order Model and a Higher-Order Sliding-Mode Control of the Air Supply System of a Proton-Exchange- 
Membrane Fuel Cell with Experimental Validation", In: 8th IEEE International Conference of Advanced Electromechanical Motion Systems \& Electric Drives, Lille, (2009) 1-6.

12. Kunusch, C., Puleston, P.F., Mayosky, M.A. and Riera J., "Sliding Mode Strategy for PEM Fuel Cells Stacks Breathing Control Using a Super-Twisting Algorithm", IEEE Transactions on Control Systems Technology, Vol. 17, (2009), 167-174.

13. Kunusch, C., Puleston, P.F., Mayosky, M.A. and Serra M., "Advances in HOSM control design and implementation for PEM fuel cell systems," In: 14th International Conference on Methods and Models in Automation and Robotics, Miedzyzdroje, Poland, (2009), 709-716.

14. Matraji, I., Laghrouche, S. and Wack, M.,"Second order sliding mode control for PEM Fuel Cells", In: 49th IEEE Conference on Decision and Control (CDC), (2010), 2765-2770.

15. Matraji, I., Laghrouche, S. and Wack, M.,"Pressure control in a PEM fuel cell via second order sliding mode", International Journal of Hydrogen Energy, Vol. 37, (2012), 16104-16116.

16. Levent, A., "Robust exact differentiation via sliding mode technique," Automatica, Vol. 34, 379-384, 1998.

17. Levant, A., "Higher-order sliding modes, differentiation and output-feedback control", International Journal of Control, Vol. 76, (2003), 924-941.

18. Cannas, B., Cincotti, S. and Usai, E., "Chaos Synchronization via Sliding Modes", In: AIP Conference of 4th International Conference Computing Anticipatory System, CASYS 2000, New York,(2001), 229 - 241.

19. Pisano, A. and Usai, E., "Sliding mode control: A survey with applications in math", Mathematics and Computers in Simulation, Vol. 81, (2011), 954-979.

20. Pisano,A.,"Second Order Sliding Modes: Theory and Applications", $\mathrm{PhD}$, Dipartimento di Ingegneria Elettrica ed Elettronica (DIEE) Universit'a degli Studi di Cagliari, Cagliari,Italia, (2000).

21. Levant, A.,"Principles of 2-sliding mode design," Automatica, Vol. 43, (2007), 576-586.

22. Levant, A.,"Sliding order and sliding accuracy in sliding mode control," International Journal of Control, Vol. 58, (1993), 1247-1263.

23. Bartolini, G., Ferrara, A., Pisano, A. and Usai, E., "On the convergence properties of a 2 -sliding control algorithm for nonlinear uncertain systems", International Journal of Control, Vol.74, (2001), 718-731.

24. Bartolini, G., Pisano, A., Punta, E. and Usai, E.,"A survey of applications of second-order sliding mode control to mechanical systems", International Journal of Control, Vol. 76, (2003), 875-892.

25. Moreno, J.,"A linear framework for the robust stability analysis of a generalized super-twisting algorithm", In: 6th International Conference Electrical Engineering, Computing Science and Automatic Control, Toluca, (2009), 12-17.

26. Cruz-Zavala, E., Moreno, J. and Fridman, L., "Uniform SecondOrder Sliding Mode Observer for Mechanical Systems", In: 11th International Conference Variable Structure Systems, Mexico City, Mexico, (2010), 14-15.

\section{Appendix A}

\section{Lemma 1.}

For real numbers $a>0, b>0, c>0, p>1, q>1$, concerning $\frac{1}{p}+\frac{1}{q}=1$, the following inequality is held:

$a \cdot b \leq c^{p} \frac{a^{p}}{p}+c^{-q} \frac{b^{q}}{q}$

A. 1 Proof of Theorem $1 . \quad$ (i) It is primarily shown that $V_{2}(\mathrm{e})$ is positive definite. Applying Young's (A. 1) inequalities to $V_{2}(e)$ in (30), yields:

$V_{2}(\mathrm{e}) \geq \frac{\sigma}{2} \cdot k_{2} \cdot\left|\mathrm{e}_{1}\right|^{2}+\frac{\sigma}{2} \cdot\left|\mathrm{e}_{2}\right|^{2}-\left(\frac{\gamma_{1}^{2}}{2}\left|\mathrm{e}_{1}\right|^{2}+\frac{\gamma_{1}^{-2}}{2}\left|\mathrm{e}_{2}\right|^{2}\right)$

A simple factorization implies:

$V_{2}(\mathrm{e}) \geq\left(\frac{\sigma}{2} \cdot k_{2}-\frac{\gamma_{1}^{2}}{2}\right) \cdot\left|\mathrm{e}_{1}\right|^{2}+\left(\frac{\sigma}{2}-\frac{\gamma_{1}^{-2}}{2}\right) \cdot\left|\mathrm{e}_{2}\right|^{2}$

In order to make $V_{2}(\mathrm{e})$ positive, it is necessary to have:

$\left.\begin{array}{l}\left(\frac{\sigma}{2} \cdot k_{2}-\frac{\gamma_{1}^{2}}{2}\right)>0 \\ \left(\frac{\sigma}{2}-\frac{\gamma_{1}^{-2}}{2}\right)>0\end{array}\right\} \Rightarrow \quad \sigma>\frac{\gamma_{1}^{2}}{k_{2}}, \sigma>\gamma_{1}^{-2} \Rightarrow \sigma>\left\{\frac{\gamma_{1}^{2}}{k_{2}}, \gamma_{1}^{-2}\right\}$

It expresses a bound to make the positivity of the Lyapunov candidate $V_{2}(\mathrm{e})$ valid.

(ii) Here, it is shown that the derivative of $V_{2}(e)$ along with the trajectories of (27) and (28) becomes negative.

$$
\begin{aligned}
& V_{2}(\mathrm{e})=\underbrace{\left(\sigma \cdot k_{2} \cdot e_{1} \cdot e_{2}+k_{1} \cdot \mu \cdot e_{1} \cdot e_{2}-\sigma \cdot k_{2} \cdot \mu^{2} \cdot e_{2} \cdot e_{1}\right)} \\
& +\underbrace{\left(k_{2} \mu^{2} \cdot \mathrm{e}_{1}^{2}-\sigma \cdot k_{1} \cdot k_{2} \cdot \mu \cdot\left|\mathrm{e}_{1}\right|^{2}\right)} \\
& \underbrace{\left(-\sigma \cdot k_{1} \cdot k_{2} \cdot\left|\mathrm{e}_{1}\right|^{\frac{3}{2}}+\frac{3}{2} \cdot \mu \cdot k_{2} \cdot\left|\mathrm{e}_{1}\right|^{\frac{3}{2}} \cdot \operatorname{sign}\left(\mathrm{e}_{1}\right)\right)}_{3} \\
& +\underbrace{\left(\frac{\left|e_{1}\right|}{2} \cdot k_{2}\right)}_{4} \\
& +\underbrace{\left(-\frac{3}{2} \cdot \mu \cdot \sigma \cdot k_{2} \cdot e_{2} \cdot\left|\mathrm{e}_{1}\right|^{\frac{1}{2}} \operatorname{sign}\left(\mathrm{e}_{1}\right)+k_{1} \cdot \mathrm{e}_{2} \cdot\left|\mathrm{e}_{1}\right|^{\frac{1}{2}} \operatorname{sign}\left(\mathrm{e}_{1}\right)\right)}- \\
& \underbrace{\sigma \cdot k_{2} \cdot e_{2} \cdot \frac{\operatorname{sign}\left(\mathrm{e}_{1}\right)}{2}-}_{6}-\underbrace{\mathrm{e}_{2}^{2}}_{7}+\underbrace{\mathrm{e}_{1} \cdot \dot{\varsigma_{1}}}_{\text {ExtraTerm Extra Term }}
\end{aligned}
$$

A use of the inequality (A.1), assuming $\forall \gamma_{i}>0$ yields:

$$
\begin{aligned}
& 3=\left|e_{1}\right| \cdot\left|e_{2}\right| \leq \frac{\gamma_{1}^{2}}{2} \cdot\left|e_{1}\right|^{2}+\frac{\gamma_{1}^{-2}}{2} \cdot\left|e_{2}\right|^{2}, p=2, q=2 \\
& 5=\left|e_{1}\right|^{\frac{1}{2}} \cdot\left|e_{2}\right| \leq \frac{\gamma_{3}^{3}}{3}\left|e_{1}\right|^{\frac{3}{2}}+\frac{2}{3} \gamma_{3}^{-\frac{3}{2}}\left|e_{2}\right|^{\frac{3}{2}}, p=3, q=\frac{3}{2}
\end{aligned}
$$

Therefore, the Lyapunov function is bounded by the following norm: 
$\dot{V}_{2}(\mathrm{e}) \leq-C_{1} \cdot\|\mathrm{e}\|-\beta_{1} \cdot\left|\mathrm{e}_{1}\right|^{\frac{3}{2}}+\beta_{2} \cdot\left|\mathrm{e}_{2}\right|^{\frac{3}{2}}+C_{2} \cdot\|\mathrm{e}\|$

$\Rightarrow \dot{V}_{2}(\mathrm{e}) \leq-\frac{C_{1}}{2} \cdot\|\mathrm{e}\|^{2}-\frac{C_{1}}{2} \cdot\|\mathrm{e}\|\left(\frac{2 \beta_{2}}{C_{1}} \cdot\|\mathrm{e}\|^{\frac{1}{2}}-\frac{2 C_{2}}{C_{1}}\right)$

$C_{1}=\min \left\{\alpha_{1}, \alpha_{2}\right\}$

$C_{2}=\max \left\{\beta_{3}, \beta_{4}\right\}$

where:

$\alpha_{1}=\left(-\left(k_{2} \mu^{2}-\sigma \cdot k_{1} \cdot k_{2} \cdot \mu\right)-\left(\sigma \cdot k_{2}+k_{1} \cdot \mu-\sigma \cdot k_{2} \cdot \mu^{2}\right) \cdot \frac{\gamma_{1}^{2}}{2}\right)$

$\alpha_{2}=\left(1-\left(\sigma \cdot k_{2}+k_{1} \cdot \mu-\sigma \cdot k_{2} \cdot \mu^{2}\right) \cdot \frac{\gamma_{1}^{-2}}{2}\right)$

$\beta_{1}=\left(-\frac{3}{2} \cdot \mu \cdot k_{2}+\sigma \cdot k_{1} \cdot k_{2}-k_{1} \cdot \frac{\gamma_{3}^{3}}{3}+\frac{1}{2} \cdot \mu \cdot \sigma \cdot k_{2} \cdot \gamma_{3}^{3}\right)$

$\beta_{2}=\frac{2}{3} \cdot k_{1} \cdot \gamma_{3}^{-\frac{3}{2}}-\mu \cdot \sigma \cdot k_{2} \cdot \gamma_{3}^{-\frac{3}{2}}, \beta_{3}=\left(\frac{k_{2}}{2}+\dot{\zeta}_{1}\right), \beta_{4}=\sigma\left(\dot{\zeta}_{1}-k_{2}\right), \dot{\zeta}_{1}=L$

A solution of the differential Equation (A. 5) is given by:

$$
\begin{aligned}
& \left\{\begin{array}{l}
\frac{V(\mathrm{e})}{C_{4}} \leq\|\mathrm{e}\|^{2} \\
\dot{V}(\mathrm{e}) \leq-\frac{C_{1}}{2} \cdot\|\mathrm{e}\|^{2}
\end{array} \Rightarrow \dot{v}(t) \leq-\frac{C_{1}}{2 \cdot C_{4}} \cdot v(t) \Rightarrow \frac{\dot{v}(t)}{V(t)} \leq-\frac{C_{1}}{2 \cdot C_{4}}\right. \\
& \Rightarrow \ln (v(t)) \leq-\frac{C_{1}}{2 \cdot C_{4}} \Rightarrow v(t) \leq v(0) \cdot \exp \left(-\frac{C_{1}}{2 \cdot C_{4}} \cdot t_{1}\right) \\
& \Rightarrow v(t) \leq v(0) \cdot \exp \left(-\frac{C_{1}}{2 \cdot C_{4}} \cdot t_{1}\right) \Rightarrow t_{1}\left(\varepsilon, V_{0}\right) \leq-\frac{2 \cdot C_{4}}{C_{1}} \cdot \ln \left(\frac{\varepsilon}{V_{0}}\right) \\
& V_{f}=\varepsilon
\end{aligned}
$$

This confirms that system (27) and (28) forces the error states to get in the level $\operatorname{set}\left\{\mathrm{e} \mid V_{2}(\mathrm{e})<\varepsilon\right\} \quad$ in a time less than $t_{1}\left(\varepsilon, v_{0}\right)$.

\section{Systematic Approach to Design a Finite Time Convergent Differentiator in Second Order Sliding Mode Controller}

S. M. Rakhtala, A. Ranjbar, R. Ghaderi

Faculty of Electrical and Computer Engineering, Babol University of Technology, Iran

\section{PAPER INFO}

Paper history:

Received 30 November 2012

Received in revised form 23 January 2013

Accepted 18 April 2013

\section{Keywords:}

Finite Time Convergent

Nonlinear Modeling

Twisting Algorithm

Convergent Differentiator

Pressure Regulation.
در اين مقاله يك روش قانونمند براى طراحى مشتق كير با الكوريتم سويرتو يستينخ بر مبناى تابع ليايانف ارائه شده است.

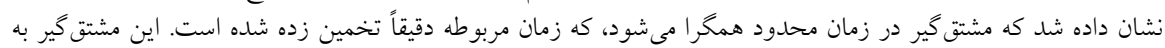

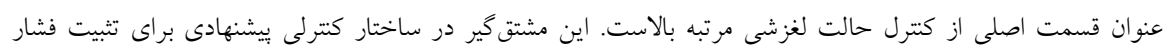

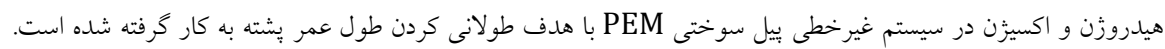

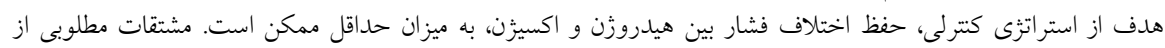

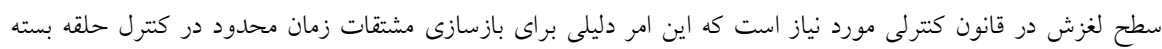

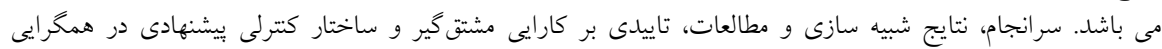
تخمين در زمان محدود است.

doi: 10.5829/idosi.ije.2013.26.11b.11 


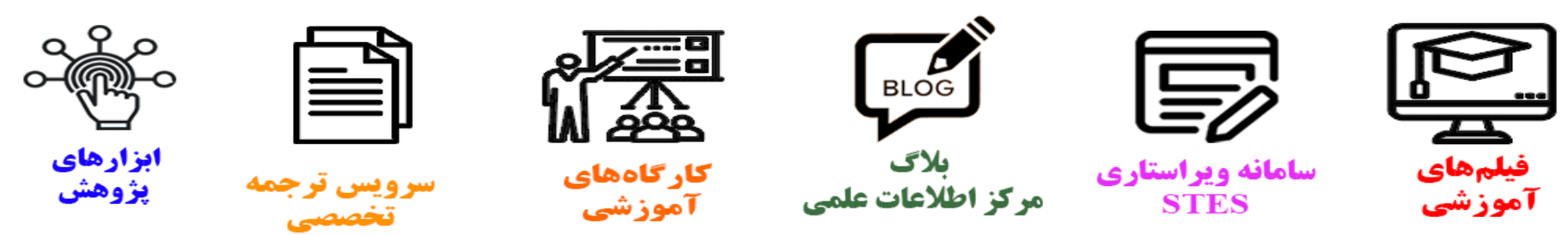

\section{(c)}

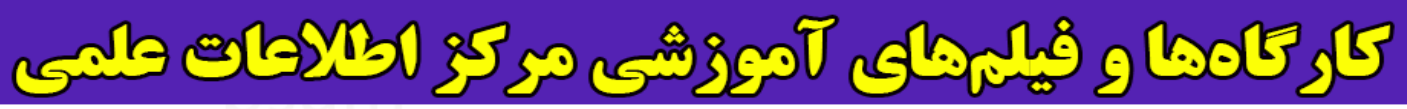
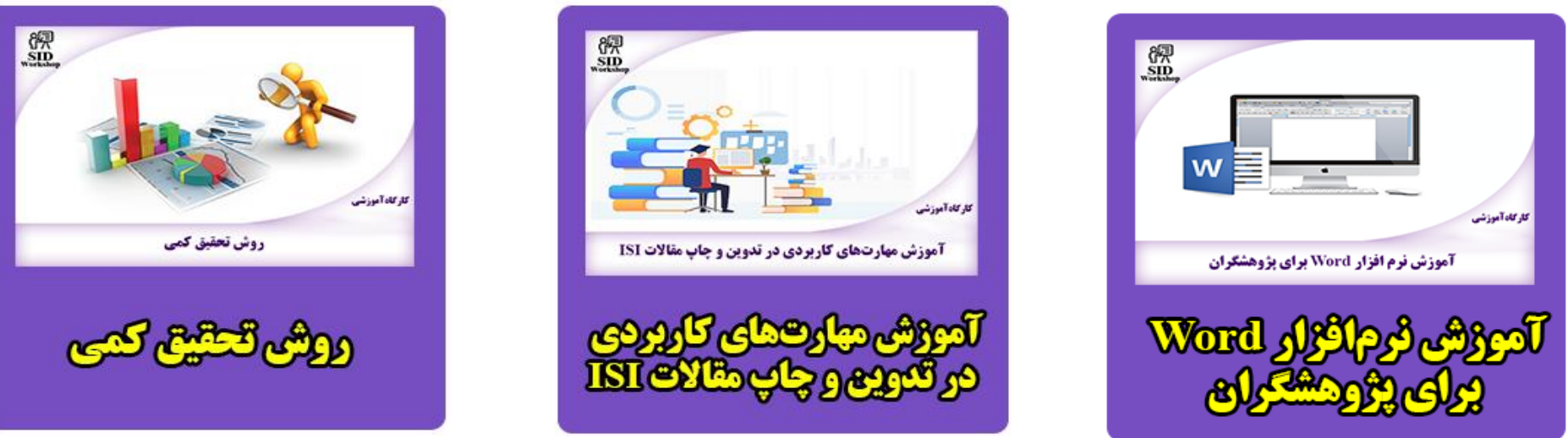